follow-up (FU) in a series of patients treated with the Contour device.

Materials and Methods Thirty-four aneurysms in 31 patients (21 Females, 10 males; mean age: 59 ys.) treated by the Contour device were included in the study. Thirty aneurysms were unruptured,3 recanalized and one ruptured. The aneurysm locations were: 14 Acom complex, 8middle cerebral artery, 3 Pcom/PCA, 2 Ophthalmic, 1 AChA, 1 Sup. Hyp., 1 ICA bifurcation, 2 Tip Basilar, 1 ASCA, 1 PICA.The angiographic follow-up at 24 hour was available in 30/34 aneurysms and midterm (3-6 mo) FU is available in 24/34 aneurysms. mRS evaluation at 1 month was available in all cases.

Results Contour procedure was successful in 32 cases and failed in two. No procedural angiographic complications were observed. Angiographic results at 24 hours were:complete occlusion in $20 \%(6 / 30)$ of aneurysms, neck remnant in $43 \%$ $(13 / 30)$, and aneurysm residual opacification in 37\% (11/30). Compared with the results observed immediately after the procedure, the occlusion rate observed at the 24-hour angiographic follow-up, was not modified in $57 \%$ of the aneurysms (17/30) and improved in 13 (43\%). The evaluation of the occlusion rate at mid-term follow-up showed occlusion in $46 \%$ of aneurysms (11/24), neck remnant in $37.5 \%(9 / 24)$ and residual aneurysm in $16.5 \%(4 / 24)$. There was no aneurysm bleeding during the periprocedural and FU period.There was no mortality. A transient postoperative morbidity was observed in the ruptured aneurysm unrelated to the device. Another patient suffered from a reversible contrast-induced encephalopathy. Preprocedural mRS was 0 in 30 patients and 1 in one. At 3-6 mo FU, mRS in relation to pre-treatment state was unchanged in all patients.

Conclusion The use of Contour device is an effective and relatively safe technique in the treatment of intracranial aneurysms. However, more experience and long-term follow-up are needed.

Disclosures A. Biondi: None. G. Vitale: None. P. Primikiris: None. S. Ferhat: None. G. Charbonnier: None.

\section{LB-009 RETREATMENT OF RESIDUAL AND RECURRENT ANEURYSMS FOLLOWING EMBOLIZATION WITH THE WOVEN ENDOBRIDGE (WEB) DEVICE: MULTICENTER CASE SERIES}

\begin{abstract}
${ }^{1} V$ Srinivasan* ${ }^{*}{ }^{2} A$ Dmytriw, ${ }^{3} R$ Regenhardt, ${ }^{2}$ J Vicenty-Padilla, ${ }^{4} \mathrm{M}$ Aziz-Sultan, ${ }^{5} \mathrm{~A}$ Patel, ${ }^{6} \mathrm{~N}$ Alotaibi, ${ }^{7} \mathrm{E}$ Levy, ${ }^{8} \mathrm{M}$ Waqas, ${ }^{9} \mathrm{~J}$ Cherian, ${ }^{10} \mathrm{~J}$ Johnson, ${ }^{11} \mathrm{P}$ Jabbour, ${ }^{11} \mathrm{~A}$ Sweid, ${ }^{12} \mathrm{~B}$ Gross, ${ }^{13} \mathrm{R}$ Starke, ${ }^{14} \mathrm{~A}$ Puri, ${ }^{14} \mathrm{~F}$ Massari, ${ }^{15} \mathrm{C}$ Griessenauer, ${ }^{11} \mathrm{C}$ Catapano, ${ }^{1} \mathrm{C}$ Rutledge, ${ }^{10} \mathrm{O}$ Tanweer, ${ }^{16} \mathrm{P}$ Yashar, ${ }^{17} \mathrm{G}$ Cortez, ${ }^{17} \mathrm{R}$ Hanel, ${ }^{1} \mathrm{~A}$ Ducruet, ${ }^{1} \mathrm{~F}$ Albuquerque, ${ }^{1} \mathrm{M}$ Lawton, ${ }^{18} \mathrm{P}$ Kan. ${ }^{1}$ Neurosurgery, Barrow Neurological Institute, Phoenix, AZ; ${ }^{2}$ Radiology, Brigham and Women's Hospital, Boston, MA; ${ }^{3}$ Neurolnterventional, Massachusetts General Hospital, Boston, MA; ${ }^{4}$ Neurosurgery, Brigham and Women's Hospital, Boston, MA; ${ }^{5}$ Neurolnterventional Program, Massachusetts General Hospital, Boston, MA; ${ }^{6}$ Neurosurgery, Massachusetts General Hospital, Boston, MA; ${ }^{7}$ Jacobs School of Medicine at Biomedical Sciences, Buffalo, NY; ${ }^{8}$ Neurosurgery, Jacobs School of Medicine at Biomedical Sciences, Buffalo, NY; ${ }^{9}$ Neurosurgery, University of Maryland, Baltimore, MD; ${ }^{10}$ Neurosurgery, Baylor College of Medicine, Houston, TX; ${ }^{11}$ Neurosurgery, Thomas Jefferson University, Philadelphia, PA; ${ }^{12}$ Neurosurgery, University of Pittsburgh, Pittsburgh, $P A$; ${ }^{13}$ Neurosurgery, University of Miami, Miami, FL; ${ }^{14}$ University of Massachusetts, Worcester, MA; ${ }^{15}$ Neurosurgery, Geisinger, Danville, PA; ${ }^{16}$ Neurosurgery, Yashar Neurosurgery, Los Angeles, $C A ;{ }^{17}$ Neurosurgery, Lyerly Neurosurgery, Jacksonville, $F L ;{ }^{18}$ Neurosurgery, University of Texas Medical Branch, Galveston, TX
\end{abstract}

10.1136/neurintsurg-2021-SNIS.250

Objective The Woven EndoBridge (WEB) device was approved by the U.S. Food and Drug Administration (FDA) as the first intrasaccular device for intracranial aneurysm treatment in December 2018. Its use has become more common since then, but both trial results and post-market experiences have raised questions about efficacy in achieving complete aneurysm obliteration. Retreatment after WEB embolization has not been extensively discussed.

Methods Retrospective review across 13 institutions identified all occurrences of WEB retreatment within neurovascular databases. Details regarding demographics, aneurysm characteristics, treatment considerations, clinical outcomes, and aneurysm occlusion were obtained and analyzed.

Results Twenty-nine aneurysms were retreated in 29 patients. Endovascular methods were used for 22 cases and 7 were treated surgically. Endovascular treatments included stentassisted coiling (12), flow diversion (6), coiling (2), PulseRider-assisted coiling (1), and additional WEB placement (1). Surgical treatments included primary clipping (6) and Hunterian ligation (1). There were no major complications within the study group.

Conclusions WEB retreatments were successfully performed by a variety of techniques, including stent-assisted coiling, clipping, and flow diversion as the most common. These procedures were performed safely with subsequent obliteration of most aneurysms. The potential need for retreatment of aneurysms should be considered during primary WEB treatments. Disclosures V. Srinivasan: None. A. Dmytriw: None. R. Regen-

\section{WEB Retreatment Strategies}

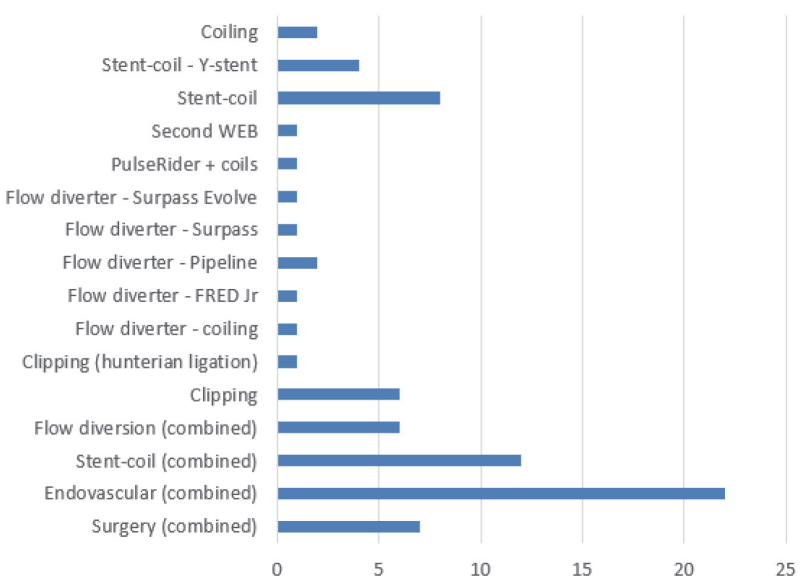

Abstract LB-009 Figure 1

hardt: None. J. Vicenty-Padilla: None. M. Aziz-Sultan: None.

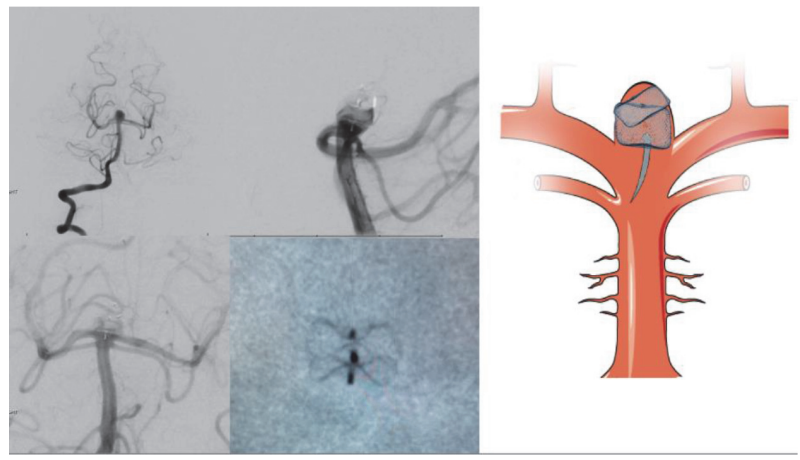

Abstract LB-009 Figure 2 


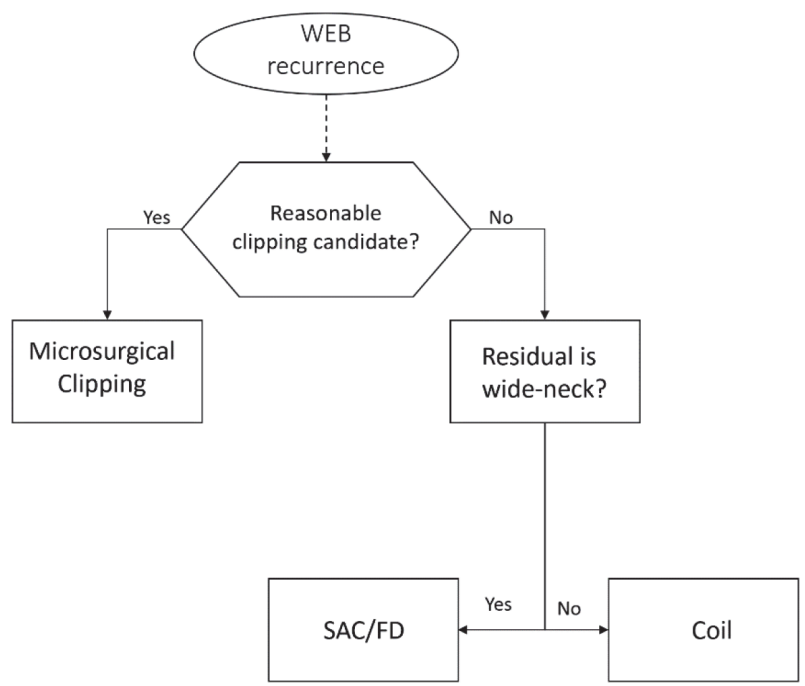

Abstract LB-009 Figure 3

A. Patel: None. N. Alotaibi: None. E. Levy: None. M. Waqas: None. J. Cherian: None. J. Johnson: None. P. Jabbour: None. A. Sweid: None. B. Gross: None. R. Starke: None. A. Puri: None. F. Massari: None. C. Griessenauer: None. J. Catapano: None. C. Rutledge: None. O. Tanweer: None. P. Yashar: None. G. Cortez: None. R. Hanel: None. A. Ducruet: None. F. Albuquerque: None. M. Lawton: None. P. Kan: None.

\section{LB-010 FIVE-YEAR RESULTS OF THE SCENT TRIAL WITH SURPASS FLOW DIVERTERS TO TREAT LARGE OR GIANT WIDE-NECK ANEURYSMS}

${ }^{1} \mathrm{P}$ Meyers ${ }^{*},{ }^{2} \mathrm{~A}$ Wakhloo, ${ }^{3} \mathrm{~A}$ Coon, ${ }^{4} \mathrm{P}$ Kan, ${ }^{5} \mathrm{R}$ Hanel. ${ }^{1}$ Departments of Radiology and Neurological Surgery, Columbia University, New York, NY; ${ }^{2}$ Department of Neurolnterventional Radiology, Beth Israel Lahey Health, Tufts University Medical School, Burlington, MA; ${ }^{3}$ Carondelet Neurosurgical Institute of St. Joseph's Hospital, Tuscon, AZ; ${ }^{4}$ Department of Neurosurgery, University of Texas Medical Center, Galveston, TX; ${ }^{5}$ Lyerly Neurosurgery, Jacksonville, FL

\subsection{6/neurintsurg-2021-SNIS.251}

Introduction The Surpass Flow Diverter provides a minimally invasive, single flow diverter treatment option for patients suffering from large or giant intracranial aneurysms (IA) arising from the internal carotid artery (ICA) to the ICA terminus. Long-term clinical outcomes following the Surpass Flow
Diverter treatment of large or giant wide-neck aneurysms has not been demonstrated.

Objective To report on 5-year safety and efficacy outcomes of patients treated in the Surpass Intracranial Aneurysm Embolization System Trial to treat large or giant wide-neck aneurysms (SCENT Trial).

Methods In this multi-center and prospective trial, 180 aneurysms in 180 subjects were treated with the flow diverter system. Patients were followed per a standardized protocol at 1 month, 6 months and every year through 5 years. Aneurysm occlusion, in-stent stenosis, modified Rankin Scale scores, and complications were recorded.

Results From October 2012 through November 2015, 180 subjects were treated at 26 sites. Five-year clinical follow up completion rate was $96.7 \%$. The primary endpoint of complete aneurysm occlusion without clinically significant parent artery stenosis or retreatment at one year (62.8\%) was previous reported. Aneurysm occlusion (Raymond Class I) for those patients with angiographic follow-up progressively increased over time to $77.8 \%(91 / 117)$ and $90.2 \%(74 / 82)$ at 3 and 5 years. The cumulative proportion of subjects experiencing new or worsening major ipsilateral stroke, as adjudicated by the CEC, was $12.2 \%(22 / 180)$ and $12.8 \%(23 / 180)$ subjects at 3 and 5 years. Four patients $(2.2 \%, 4 / 180)$ experienced aneurysm rupture within the first-week post target aneurysm treatment. No additional late aneurysm ruptures occurred through the five-year follow-up. Five aneurysms $(2.8 \%)$ were retreated in the study. New serious adverse events at 3 and 5 years were noted in 15.4\% (23/149) and $9.8 \%(12 / 123)$ of subjects. Five neurological deaths occurred within one year, and one additional neurological death was reported after the subject's 5-year follow up.

Conclusions Our 5-year findings demonstrate the long-term safety and effectiveness of the Surpass Flow Diverter for intracranial aneurysm treatment, supported by high occlusion rates and low rates of delayed adverse events in this study.

Disclosures P. Meyers: 2; C; Stryker, Medtronic, Penumbra. A. Wakhloo: 1; C; Philips Medical. 2; C; Stryker. 3; C; SCENT trial (Surpass Intracranial Aneurysm Embolization System Pivotal Trial to Treat Large or Giant Wide Neck Aneurysms) presentations. 4; C; InNeuroCo., NovaSignal, Rist, Analytics 4 Life, ThrombX. A. Coon: 2; C; Stryker, Medtronic, Microvention, InNeuroCo. P. Kan: 2; C; Stryker, Imperative Care. 4; C; InNeuroCo. R. Hanel: 1; C; Medtronic, Stryker, Microvention, Cerenovus. 2; C; Stryker, Medtronic, Cerenovus, Microvention. 4; C; Neurvana, Elum, EndoStream, Three Rivers Medical Inc., Rist, Cerebrotech, InNeuroCo.. 6; C; MIVI, Elum, Three Rivers Medical Inc., Shape Medical. 